\title{
Monitoring Insecticide Susceptibility in Aedes Aegypti Populations from the Two Biggest Cities, Ouagadougou and Bobo-Dioulasso, in Burkina Faso: Implication of Metabolic Resistance
}

\author{
Moussa Namountougou ${ }^{1,2,3, *, \dagger}$, Dieudonné Diloma Soma ${ }^{1,2,3, \dagger}$, Mahamoudou Balboné ${ }^{4, \ddagger}$, \\ Didier Alexandre Kaboré ${ }^{1,2, \ddagger}$, Mahamadi Kientega ${ }^{1,2, \ddagger}$, Aristide Hien ${ }^{1,2}$, Ahmed Coulibaly ${ }^{5}$, \\ Parfait Eric Ouattara 1,2, Benson Georges Meda 1,2, Samuel Drabo ${ }^{4}$, Lassane Koala 1,2, \\ Charles Nignan ${ }^{1,2}$ (D), Thérèse Kagoné ${ }^{2}$, Abdoulaye Diabaté ${ }^{1,2}$, Florence Fournet ${ }^{6}$ (D), \\ Olivier Gnankiné ${ }^{4}$ and Roch Kounbobr Dabiré ${ }^{1,2, *}$ \\ 1 Institut de Recherche en Sciences de la Santé (IRSS), Bobo-Dioulasso BP 545, Burkina Faso; \\ ddsoma@irss-dro.bf (D.D.S.); dakabore@irss-dro.bf (D.A.K.); mkientega@irss-dro.bf (M.K.); \\ ahien@irss-dro.bf (A.H.); peric.ouattara@centre-muraz.bf (P.E.O.); bgmeda@irss-dro.bf (B.G.M.); \\ lkoala@irss-dro.bf (L.K.); cnignan@irss-dro.bf (C.N.); adiabate@ic.ac.uk (A.D.) \\ 2 Département des Sciences Biomédicales, Centre Muraz, Bobo-Dioulasso BP 390, Burkina Faso; \\ therese.kagone@centre-muraz.bf \\ 3 Institut Supérieur des Sciences de la Santé, Université Nazi Boni, Bobo-Dioulasso BP 1091, Burkina Faso \\ 4 Département de Biologie et de Physiologie Animales, Université Joseph Ki-Zerbo, Ouagadougou BP 7021, \\ Burkina Faso; mahamoudou.balbone@univ-ouaga.bf (M.B.); samuel.drabo@univ-ouaga.bf (S.D.); \\ olivier.gnankine@univ-ouaga.bf (O.G.) \\ 5 Unité de Formation et de Recherche en Sciences et Techniques, Université Norbert Zongo, Koudougou BP \\ 376, Burkina Faso; ahmed.coulibaly@univ-ouaga.bf \\ 6 Maladies Infectieuses et Vecteurs: Écologie et Contrôle (MIVEGEC), Univ Montpellier, CNRS, IRD, \\ 34394 Montpellier, France; florence.fournet@ird.fr \\ * Correspondence: mnamount@ic.ac.uk (M.N.); rkdabire@irss-dro.bf (R.K.D.) \\ + Namountougou Moussa and Soma Diloma Dieudonné contributed equally to this work. \\ $\ddagger$ These authors contributed equally to this work.
}

Received: 12 January 2020; Accepted: 28 February 2020; Published: 27 May 2020

\begin{abstract}
In West Africa, Aedes aegypti remains the major vector of dengue virus. Since 2013, dengue fever has been reemerging in Burkina Faso with annual outbreaks, thus becoming a major public health problem. Its control relies on vector control, which is unfortunately facing the problem of insecticide resistance. At the time of this study, although data on phenotypic resistance were available, information related to the metabolic resistance in Aedes populations from Burkina Faso remained very scarce. Here, we assessed the phenotypic and the metabolic resistance of Ae. aegypti populations sampled from the two main urban areas (Ouagadougou and Bobo-Dioulasso) of Burkina Faso. Insecticide susceptibility bioassays to chlorpyriphos-methyl $0.4 \%$, bendiocarb $0.1 \%$ and deltamethrin $0.05 \%$ were performed on natural populations of Ae. aegypti using the WHO protocol. The activity of enzymes involved in the rapid detoxification of insecticides, especially non-specific esterases, oxidases (cytochrome P450) and glutathione-S-transferases, was measured on individual mosquitos. The mortality rates for deltamethrin $0.05 \%$ were low and ranged from $20.72 \%$ to $89.62 \%$ in the Bobo-Dioulasso and Ouagadougou sites, respectively. When bendiocarb $0.1 \%$ was tested, the mortality rates ranged from $7.73 \%$ to $71.23 \%$. Interestingly, in the two urban areas, mosquitoes were found to be fully susceptible to chlorpyriphos-methyl $0.4 \%$. Elevated activity of non-specific esterases and glutathione-S-transferases was reported, suggesting multiple resistance mechanisms involved in Ae. aegypti populations from Bobo-Dioulasso and Ouagadougou (including cytochrome P450). This update to the insecticide resistance status within Ae. aegypti populations in
\end{abstract}


the two biggest cities is important to better plan dengue vectors control in the country and provides valuable information for improving vector control strategies in Burkina Faso, West Africa.

Keywords: Aedes aegypti; dengue; insecticide susceptibility; metabolic resistance; Burkina Faso

\section{Background}

Dengue is now the most important emerging mosquito viral disease and constitutes a major public health threat in disease-endemic regions [1]. Up to now, four serotypes (DENV1, DENV2, DENV3, DENV4) have been found to be responsible for dengue disease. Dengue virus (Flaviviridae, Flavivirus) is transmitted during infected bites of Aedes female mosquitoes [1]. In Africa, Aedes aegypti remains one of the main dengue virus vectors [2]. In Burkina Faso, Ae. aegypti is assumed to be the main dengue vector in urban areas [3,4] and is characterized by a diurnal and crepuscular activity [5]. It is also most frequently identified at larval stages from breeding sites such as water containers and used tires [4].

In Burkina Faso, a dengue epidemic was first reported in 1925 [6] and then in 1983 [7]. Outbreaks were reported in Ouagadougou, the biggest city of Burkina Faso in 2013, 2015, and 2016 [1]. DENV2 was found in a number of cases in the 1980s, while DENV1 was found among travelers returning from Burkina Faso in the 2000s [8]. The presence of DENV3 was also observed in an European patient who had travelled in Burkina Faso [9]. In Ouagadougou, DENV2, DENV3, DENV4 were reported during a cross sectional survey done from December 2013 to January 2014 [4]. In 2016, more than 1061 cases of dengue and 15 deaths were recorded in Ouagadougou [1]. In this city, Ae. aegypti populations were found in artificial water containers such as flower pots, buckets, gutters, and tires, which are associated with human activities.

Sound knowledge on vector species bio-ecology is essential for the implementation of vector control strategies as no vaccine is available. Among the methods currently used, environmental management, mechanic elimination of the breeding habitats, chemical use and to, a lesser extent, biological agents, might be efficient against Aedes populations and consequently in reducing the incidence of the disease.

Recent reports of insecticide resistance in dengue vector populations in Burkina Faso revealed that Ae. aegypti was resistant to pyrethroid (deltamethrin $0.05 \%$ and permethrin $0.75 \%$ ) and bendiocarb $0.1 \%$, whereas it was fully susceptible to malathion $5 \%$ [10]. However, there are no available data upon the implication of detoxification enzymes in insecticide resistance within Ae. aegypti populations in Burkina Faso. This study aimed to explore this gap, evaluating the resistance level of Ae. aegypti populations to the three classes of insecticide used in public health in Burkina Faso.

\section{Methods}

\subsection{Study Area}

The study was carried out in Ouagadougou $\left(12^{\circ} 21^{\prime} 56^{\prime \prime} \mathrm{N}, 1^{\circ} 32^{\prime} 01^{\prime \prime} \mathrm{W}\right)$, the capital city in the central part of the country, and Bobo-Dioulasso $\left(11^{\circ} 10^{\prime} 59^{\prime \prime} \mathrm{N}, 4^{\circ} 16^{\prime} 59^{\prime \prime} \mathrm{W}\right)$ the second biggest city of the country in the western part of the country (Figure 1). In 2016, the population was estimated as 2,293,635 inhabitants in Ouagadougou and 780,846 inhabitants in Bobo-Dioulasso [11] Ouagadougou is located in the Sudan-Sahelian area with a short rainy season extending from June to September and an average yearly rainfall of between 600 and $900 \mathrm{~mm}$. Bobo-Dioulasso is located in the Sudan savannah zone. The rainy season extends from May to November with an average yearly rainfall above $900 \mathrm{~mm}$. 


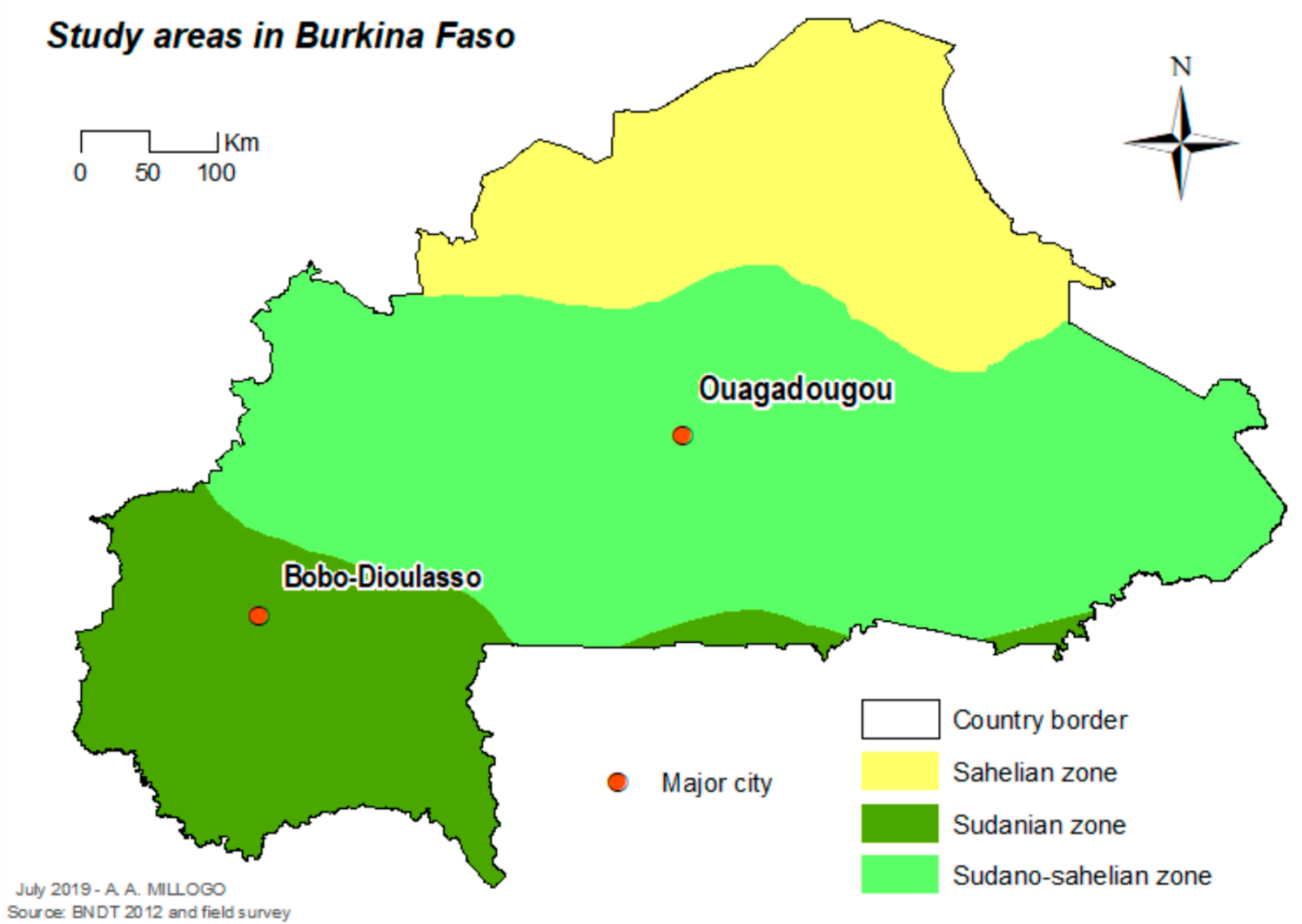

Figure 1. Localization of the study cities in Burkina Faso.

\subsection{Mosquito Collection and Rearing}

We collected Ae. aegypti mosquito larvae in the years 2013, 2014 and 2016 in a random sample of abandoned tires (twenty per site per year), found close to human dwellings. In each sample of abandoned tires, 80-100 larvae were collected and then brought back in the insectary of IRSS/DRO in Bobo-Dioulasso, where they were reared under standard controlled conditions $\left(25 \pm 2{ }^{\circ} \mathrm{C}, 80 \pm 10 \%\right.$ RH and 12:12 L-D) until adulthood. Mosquitoes were identified using morphological keys [12,13]. Adult mosquitoes issued from field collections (F0), fed with $5 \%$ sugar solution, were subsequently used for the insecticide susceptibility tests. The susceptible strain of Ae. aegypti, received from Montpellier and maintained in the insectary of IRSS, was used as control for insecticide bioassays.

\subsection{Insecticide Susceptibility Tests}

Insecticide susceptibility tests were performed on 3-5 days old females of Ae. aegypti using WHO diagnostic doses on mosquitoes collected in 2013, 2014 and 2016 [14]. The bioassays were done with papers impregnated with deltamethrin $0.05 \%$, bendiocarb $0.1 \%$ and chlorpyrifos-methyl $0.4 \%$. The wild F0 and the susceptible strain of Ae. aegypti populations were exposed to the same papers. For each insecticide paper, four replicates of 20-25 Ae. aegypti were exposed for $1 \mathrm{~h}$. For each assay, control mosquitoes were also exposed to papers only impregnated with silicon oil following the same procedure. Mortality rates were recorded $24 \mathrm{~h}$ after insecticide exposure.

\subsection{Enzyme Activities}

Biochemical assays were performed to check the activity of detoxifying enzymes, namely non-specific esterases (NSE), mixed-function oxidases (MFO) and glutathione-S-transferases (GST) involved in insecticide resistance within Ae. aegypti mosquito populations. The assays were conducted on 3-5 days old Ae. aegypti adults issued from field collections (F0) (not previously exposed to 
insecticides and stored at $-80^{\circ} \mathrm{C}$ ) using standard protocol [15]. Experimental procedures are detailed in Namountougou et al. [16,17].

\subsection{Statistical Analyses}

Mortality rates recorded during bioassays were analyzed according to the WHO criteria [18]. The populations of Ae. aegypti were classified as "resistant" if less than $90 \%$ mortality was observed, as "suspected resistant" if mortality rates were between $90 \%$ and $98 \%$ and "susceptible" for more than a $98 \%$ mortality rate. Biochemical data were analyzed and compared between the two groups (wild and susceptible strains) using non-parametric Mann-Whitney test run with Graph Pad Prism 5 software.

\section{Results}

\subsection{Insecticide Susceptibility Test}

The mortality rate in unexposed controls of wild and susceptible adult mosquito strain was less than $5 \%$ and no correction of the mortality rate was then required (Figure 2). Tests performed with deltamethrin in 2013 and 2014 on Ae. aegypti populations collected in Bobo-Dioulasso showed mortality rates $(89.62 \%$ and $82.72 \%$, respectively) lower than $90 \%$, suggesting a resistance. Mortalities of Ae aegypti collected in Ouagadougou were 50.7\% and 20.7\% for 2013 and 2014, respectively, when exposed to deltamethrin, showing a high resistance level. Two years later, in 2016, Ae. aegypti populations from Bobo-Dioulasso and Ouagadougou exhibited resistance to deltamethrin, with $60.72 \%$ and $52.54 \%$ mortality rates, respectively.

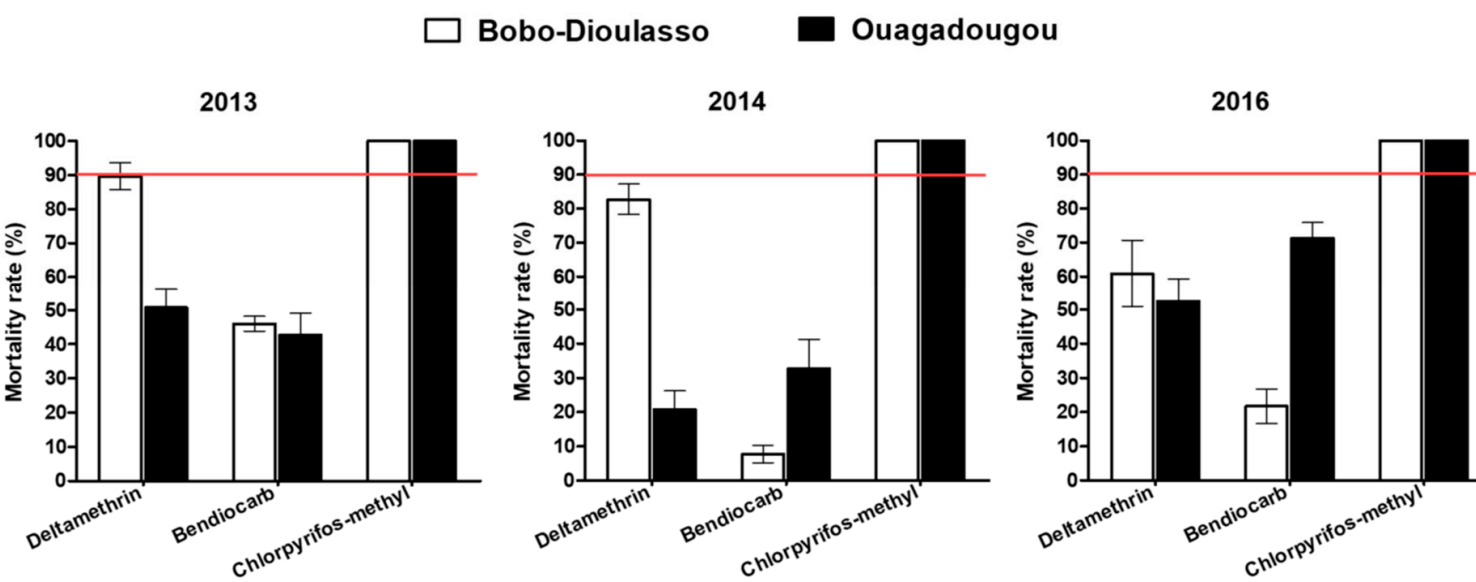

Figure 2. Mortality rates of the Aedes aegypti populations in Ouagadougou and Bobo-Dioulasso during the three years of survey. Red bars indicate the threshold of susceptibility.

During the three-year survey, Ae. aegypti populations from Ouagadougou and Bobo-Dioulasso were found to be fully resistant to bendiocarb $0.1 \%$ and the mortality rates ranged from $7.73 \%$ to $71.23 \%$. Inversely, all Ae. aegypti populations tested in 2013, 2014 and 2016 against chlorpyriphos-methyl 0.4\% were fully susceptible, with $100 \%$ of mortality rates in both cities.

\subsection{Non-Specific Esterases (NSE) and Para Nitro Phenyl Acetate (PNPA)}

The results of NSE and PNPA activities are shown in Figure 3A,B. The NSE activity within the susceptible strain of Ae. aegypti ranged from 0.006 to $0.012 \mathrm{mmol} \mathrm{NSE} / \mathrm{mg}$ protein (the median activity was 0.008). Concerning the PNPA, its activity was also high and varied from 0.410 to $1.378 \mathrm{mmol}$ $\mathrm{PNPA} / \mathrm{mg}$ protein (the median activity was 0.585 ). For both cities, the results show higher levels of esterase activity compared to the susceptible strain (Mann-Whitney test, $p<0.0001$ ). 

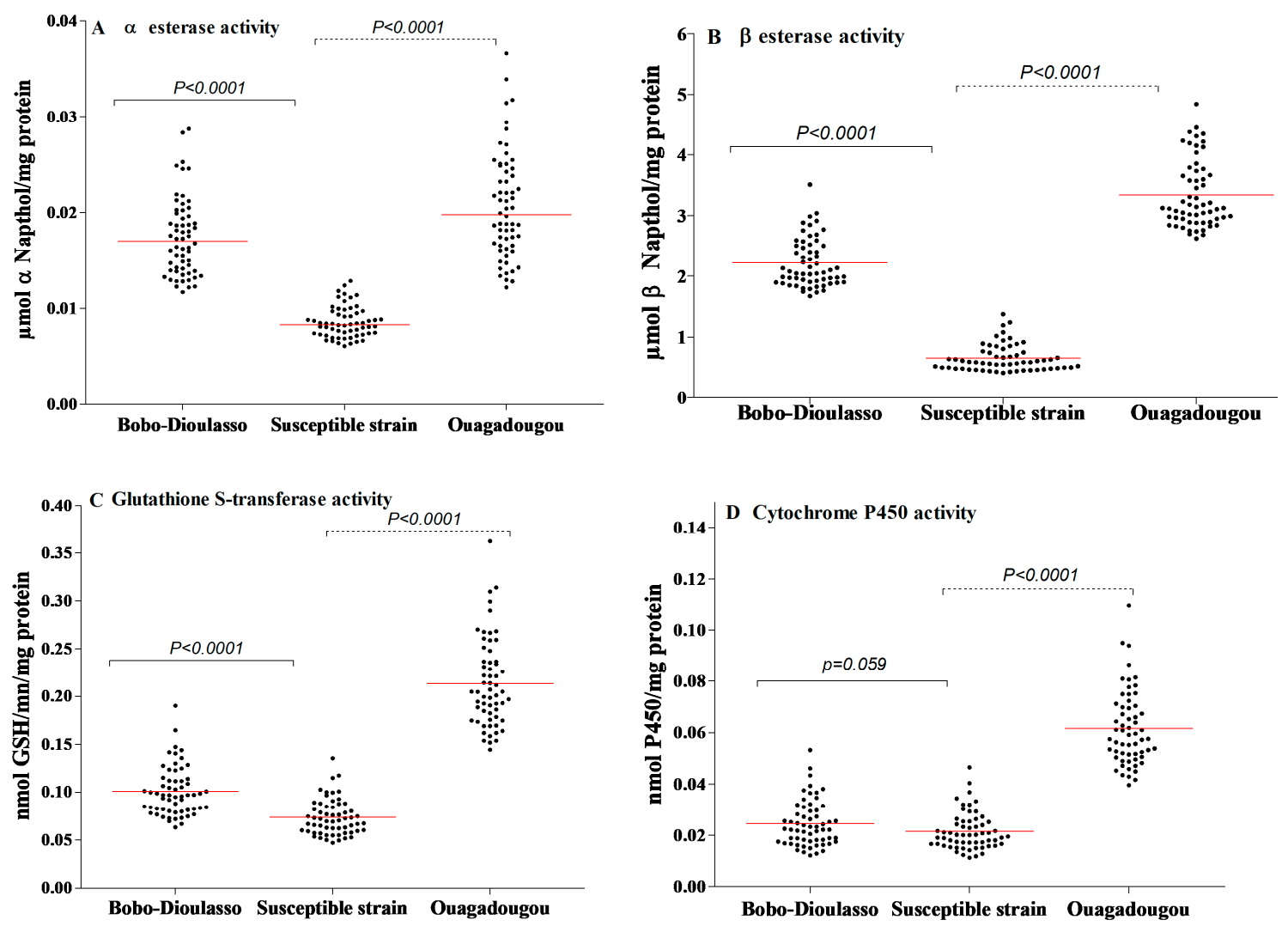

Figure 3. Detoxifying enzyme activities in Aedes aegypti mosquitoes collected in Bobo-Dioulasso and Ouagadougou in 2016. (A) Non-specific $\alpha$ Esterase activity, (B) PPNA activity, (C) glutathione-S-transferase (GST) activity, (D) P450 activity. P-value denotes significant difference in activity level when compared to the Ae. aegypti (from Montpellier) reference strain according to the Mann-Whitney U test. Red bars indicate the median value in each strain.

\subsection{Gluthathione-S-Transferases (GST)}

The levels of GST activity within the laboratory and the field populations are shown in Figure 3C. The susceptible strain showed a GST activity ranging from 0.047 to $0.135 \mathrm{mmol} \mathrm{GSH} / \mathrm{min} / \mathrm{mg}$ protein (the median activity was 0.069 ). The activity level of GST within the wild populations was higher than that recorded in the susceptible strain (Mann-Whitney test, $p<0.0001$ in both cities).

\subsection{Oxidases (Cytochrome P450)}

The activity level of oxidase (P450) in the susceptible and wild strains is shown in Figure 3D. Oxidase activity in the susceptible strain ranged from 0.0112 to $0.0465 \mathrm{nmol} P 450 / \mathrm{mg}$ protein (the median activity was 0.020 ). A significantly higher level of $\mathrm{P} 450$ activity was detected in wild populations from Ouagadougou (Mann-Whitney test, $\mathrm{p}<0.0001$ ). However, there was no statistically difference between field and susceptible strains in Bobo-Dioulasso (Mann-Whitney test, $p=0.059$ ).

\section{Discussion}

Aedes aegypti is identified as the main dengue vector in Burkina Faso [10]. The knowledge about its susceptibility to insecticides is essential for the implementation of the suitable control of Ae. aegypti populations, especially during dengue outbreaks requiring a rapid riposte. In this study, the surveillance activities were limited to the two largest cities in the country, where dengue outbreaks have been regularly reported since 2013 [19]. Aedes aegypti populations collected in Bobo-Dioulasso and Ouagadougou were found to be fully resistant to deltamethrin and bendiocarb during the two first years (2013 and 2014) of monitoring. Bioassays carried out in 2013 indicated moderate resistance level 
with deltamethrin and reduced mortality, averaging 80\% in 2014 in Bobo-Dioulasso. Then, Ae. aegypti was found to be fully resistant to deltamethrin in 2016, with mortality rates below $61 \%$. This resistance status was already notified in 2015 by Ouattara et al. [10] along a transect from Banfora to Ouagadougou.

The resistance in the Ae. aegypti populations might be selected by the high use of insecticides in households such as aerosols and repellents to prevent nuisance, especially in urban and suburban areas, from culicid bites [10,20]. Most of these widely used mosquito control products contain at least pyrethroid insecticides [21]. According to Marcombe et al. [22], deltamethrin resistance in adult populations of Ae. aegypti was positively correlated to urbanization, deltamethrin outdoor applications and to the adult over-transcription of the genes CYP9M9 and GSTE7. It is also possible that the high selection pressure exerted on the larval populations in periurban vegetable crops has increased resistance to insecticides [23]. The use of the same insecticides in urban vegetable crops and in public health (organophosphates, OP and pyrethroids) can contribute to polluting breeding sites, leading to faster development of resistance to these compounds [24]. The dispersion of household waste and empty packaging of pesticides in urban areas also allows resistance to be selected at the time of rainwater runoff.

Also, the use of insecticides in cotton and vegetable growing areas was widely involved in the emergence of the crossed resistance DDT/pyrethroids as shown by Diabaté et al. [25] and Dabiré et al. [26] in Anopheles mosquitoes. Recently, a cross resistance DDT/pyrethroid was detected in Aedes populations of Ouagadougou and Bobo-Dioulasso (Unpublished data). Many studies across Africa have demonstrated the implication of genetic mechanisms in this cross-resistance DDT/pyrethroids within Ae. aegypti populations [27]. Several amino acid substitutions have been detected in Ae. aegypti voltage sensitive sodium channel gene (Vssc) [28]. Among them, only substitutions V1016G, V1016I, and F1534C have been shown to be strongly correlated with pyrethroid resistance [29-32]. Recently, Badolo et al. [33] showed that F1534C mutation was nearly fixed in semi-urban and urban areas of Burkina Faso but was far less common in rural areas, where the V1016I mutation frequency was also significantly lower. In addition, Badolo et al. [33] suggested the involvement of metabolic resistance mechanisms involving P450s, and perhaps esterases as a pre-exposure to PBO restored a substantial part of the susceptibility to permethrin and deltamethrin. Our study documents for the first time the variation of detoxifying enzymatic activities in the populations of Aedes of Ouagadougou and Bobo-Dioulasso.

Interestingly, the wild populations of Ae. aegypti were found to be fully susceptible to chlorpyrifos-methyl during the three-year follow-up. In Burkina Faso, and likely elsewhere in continental Africa, the demonstration of sensitivity to organophosphates suggests that insecticides of this class are interesting options for controlling epidemics. GSTs and NSE activities might therefore complement the phenotypic effect of gene mutations towards increasing resistance levels to OP and broadening the resistance spectrum to unrelated compound. High levels of GST and NSE activities were observed in both Ouagadougou and Bobo-Dioulasso populations of Ae. aegypti [34]. According to Hemingway et al. [35], enhanced NSE activity may be involved in resistance to OP and carbamate (CM) in a number of arthropod species including mosquitoes, ticks, aphids and cockroaches. Hence, NSEs could further contribute to the phenotypic resistance to pyrethroid and carbamates in Ae. aegypti from Burkina Faso. In addition, there was evidence for an overall increase in cytochrome P450 activity in the samples from Ouagadougou, as compared to the Montpellier reference strain assessed simultaneously. That may explain the major role of cytochrome P450 in the metabolic resistance of Aedes populations from Ouagadougou. In this present study, we provided evidence that insecticide multi-resistance is a common phenotype within Ae. aegypti populations from Burkina Faso, while a previous study showed that target-site mutations are widespread [33].

\section{Conclusions}

As no efficient vaccine against dengue fever exists, vector control relies on insecticide use and remains the main strategy to reduce the spread of dengue fever outbreaks. In the current survey, 
Ae. aegypti populations were found to be fully resistant to pyrethroids and carbamates in the two main cities of Burkina Faso, West Africa. For the first time, detoxification enzymes were found to be involved in the insecticide resistance within Ae. aegypti populations in Burkina Faso.

Despite this high resistance to pyrethroids and carbamates, organophosphate compounds remain effective against Aedes mosquitoes. These interesting data could be useful for health policy makers in their design strategies. Here, we pointed out the occurrence of metabolic resistance and how these results could impact the surveillance planning.

Author Contributions: R.K.D., F.F., O.G., D.D.S. and M.N. conceived and designed the experiments. D.D.S., M.N., O.G. and R.K.D. drafted the manuscript. S.D., M.B., A.C. performed biochemical analysis. D.D.S., B.G.M., M.K., P.E.O., A.H. and D.A.K. participated to the sample collections and bioassay analysis. D.D.S., M.K. and D.A.K. analysed data. A.D., T.K., L.K., C.N., F.F., O.G., D.D.S., M.N. and R.K.D. provided technical input to the analysis and revisions of the manuscript. R.K.D. coordinated the field and laboratory work. All authors have read and agreed to the published version of the manuscript.

Funding: The study was funded by LAMIVECT HC177F-2R177-GABI-LAMINM and TWAS 15-259 RG/BIO/AF/AC.

Acknowledgments: We thank Millogo Azize for his contribution to mapping.

Conflicts of Interest: The authors declare that they have no competing interests.

Availability of Data and Materials: The datasets used during the current study are available from the corresponding author on request.

$\begin{array}{ll}\text { Abbreviations } \\ \text { GST } & \text { Gluthatione S-transferase } \\ k d r & \text { Knockdown resistance } \\ \text { NS } & \text { Non-specific } \\ \text { NSE } & \text { Non-specific Esterase } \\ \text { PNPA } & \text { Para Nitro Phenyl Acetate } \\ \text { WHO } & \text { World Health Organization }\end{array}$

\section{References}

1. WHO. Dengue au Burkina Faso; Bulletin d'information sur les flambées epidémiques 2016. Available online: https://www.who.int/csr/don/18-november-2016-dengue-burkina-faso/fr/ (accessed on 5 March 2020).

2. Weetman, D.; Kamgang, B.; Badolo, A.; Moyes, C.L.; Shearer, F.M.; Coulibaly, M.; Pinto, J.; Lambrechts, L.; McCall, P.J. Aedes mosquitoes and Aedes-borne arboviruses in Africa: Current and future threats. Int. J. Environ. Res. Public Health 2018, 15, 220. [CrossRef] [PubMed]

3. Robert, V.; Lhuillier, M.; Meunier, D.; Sarthou, J.L.; Monteny, N.; Digoutte, J.P.; Cornet, M.; Germain, M.; Cordellier, R. Yellow fever virus, dengue 2 and other arboviruses isolated from mosquitos, in Burkina Faso, from 1983 to 1986. Entomological and epidemiological considerations. Bull Soc Pathl Exot 1993, 86, 90-100.

4. Ridde, V.; Agier, I.; Bonnet, E.; Carabali, M.; Dabiré, K.R.; Fournet, F.; Ly, A.; Meda, I.B.; Parra, B. Presence of three dengue serotypes in Ouagadougou (Burkina Faso): Research and public health implications. Infect. Dis. Poverty 2016, 5, 1-13. [CrossRef] [PubMed]

5. Schlenker, E.H.; Goldman, M.; Holman, G. Effect of aspartic acid on control of ventilation in androgenized and ovariectomized female rats. J. Appl. Physiol. 1992, 72, 2255-2258. [CrossRef]

6. Amarasinghe, A.; Kuritsky, J.N.; Letson, G.W.; Margolis, H.S. Dengue Virus Infection in Africa. Emerg. Infect. Dis. 2011, 17, 1349-1354. [CrossRef]

7. Roux, V.R.J.; Saluzzo, M.L.J.F.; Sarthou, J.L.; Stanciheluni, A.; Molez, G.J.F.; Some, L.; Darriet, F.; Soudret, R.; Guiguemde, T.R.; Henneqiun, M. L'epidemie de fievre jaune au Burkina Faso en 1983. Bull World Heal. Organ 1986, 64, 873-882.

8. Franco, L.; Di Caro, A.; Carletti, F.; Vapalahti, O.; Renaudat, C.; Zeller, H.; Tenorio, A. Recent expansion of dengue virus serotype 3 in West Africa. Euro Surveill. 2010, 15, 1-4.

9. Eckerle, I.; Kapaun, A.; Junghanss, T.; Schnitzler, P.; Drosten, C.; Jänisch, T. Dengue virus serotype 3 infection in traveler returning from West Africa to Germany. Emerg. Infect. Dis. 2015, 21, 175. [CrossRef] 
10. Ouattara, L.P.E.; Sangaré, I.; Namountougou, M.; Hien, A.; Ouari, A.; Soma, D.D.; Kassié, D.; Diabaté, A.; Gnankiné, O.; Bonnet, E.; et al. Surveys of Arboviruses Vectors in Four Cities Stretching Along a Railway Transect of Burkina Faso: Risk Transmission and Insecticide Susceptibility Status of Potential Vectors. Front. Vet. Sci. 2019, 6, 1-9. [CrossRef]

11. NSDI. Projections Demographiques des Communes du Burkina Faso de 2007 à 2020; INSD. 2017. Available online: https://www.insd.bf (accessed on 5 March 2020).

12. Mattingly, P.F.; Rageau, J.; La, C.A.; Des, F.; Du, M.; Xii, S.A. Contributions de la faune des moustiques du Sud-Est Asiatique. XII. Contrib. Am. Entomol. Inst. 1973, 7.

13. Mouchet, J.; Bouchite, B. Distribution et gites pre-imaginaux de quelques espèces de moustiques africains presents en Haute Volta, 1964; in press.

14. WHO. Guidelines for Laboratory and Field-Testing of Long-Lasting Insecticidal Nets; World Health Organization: Geneva, Switzerland, 2013; Who/Htm/Ntd/Whopes/2013.1.

15. WHO. Techniques to Detect Insecticide Resistance Mechanisms (Field and Laboratory Manual); World Health Organization: Geneva, Switzerland, 1998.

16. Namountougou, M.; Simard, F.; Baldet, T.; Diabaté, A.; Ouédraogo, J.B.; Martin, T.; Dabiré, R.K. Multiple Insecticide Resistance in Anopheles gambiae s.l. Populations from Burkina Faso, West Africa. PLoS ONE 2012, 7. [CrossRef] [PubMed]

17. Namountougou, M.; Soma, D.D.; Kientega, M.; Balboné, M.; Kaboré, D.P.A.; Drabo, S.F.; Coulibaly, A.Y.; Fournet, F.; Baldet, T.; Diabaté, A.; et al. Insecticide resistance mechanisms in Anopheles gambiae complex populations from Burkina Faso, West Africa. Acta Trop. 2019, 197, 105054. [CrossRef] [PubMed]

18. WHO. Test Procedures for Insecticide Resistance Monitoring in Malaria Vector Mosquitoes, 2nd ed.; World Health Organization: Geneva, Switzerland, 2016.

19. Tarnagda, Z.; Congo, M.; Sagna, T.; Ouédraogo, C.; Nikiéma, V.; Cissé, A.; Sanou, M.A.; Ouédraogo, A.; Bosco, J. Outbreak of dengue fever in Ouagadougou, Burkina Faso, 2013. Int. J. Microbiol. Immunol. Res. 2014, 2, 101-108.

20. Ponlawat, A.; Scott, J.G.; Harrington, L.C. Insecticide susceptibility of Aedes aegypti and Aedes albopictus across Thailand. J. Med. Entomol. 2005, 42, 821-825. [CrossRef]

21. Amelia-yap, Z.H.; Chen, C.D.; Sofian-azirun, M.; Low, V.L. Pyrethroid resistance in the dengue vector Aedes aegypti in Southeast Asia: Present situation and prospects for management. Parasit. Vectors 2018, 11, 1-17. [CrossRef]

22. Marcombe, S.; Mathieu, R.B.; Pocquet, N.; Riaz, M.A.; Poupardin, R.; Sélior, S.; Darriet, F.; Reynaud, S.; Yébakima, A.; Corbel, V.; et al. Insecticide resistance in the dengue vector Aedes aegypti from martinique: Distribution, mechanisms and relations with environmental factors. PLoS ONE 2012, 7. [CrossRef]

23. Ahouangninou, C.; Fayomi, B.E.; Martin, T. Evaluation des risques sanitaires et environnementaux des pratiques phytosanitaires des producteurs maraîchers dans la commune rurale de Tori-Bossito (Sud-Bénin). Cah. Agric. 2011, 20, 216-222.

24. Bharati, M.; Saha, D. Multiple insecticide resistance mechanisms in primary dengue vector, Aedes aegypti (Linn.) from dengue endemic districts of sub-Himalayan West Bengal, India. PLoS ONE 2018, 13, 1-13. [CrossRef]

25. Diabate, A.; Baldet, T.; Chandre, F.; Akogbeto, M.; Guiguemde, T.R.; Darriet, F.; Brengues, C.; Guillet, P.; Hemingway, J.; Small, G.J.; et al. The role of agricultural use of insecticides in resistance to pyrethroids in Anopheles gambiae s.1. in Burkina Faso. Am. J. Trop. Med. Hyg. 2002, 67, 617-622. [CrossRef]

26. Dabiré, K.R.; Diabaté, A.; Namountougou, M.; Toé, K.H.; Ouari, A.; Kengne, P.; Bass, C.; Baldet, T. Distribution of pyrethroid and DDT resistance and the L1014F kdr mutation in Anopheles gambiae s.l. from Burkina Faso (West Africa). Trans. R. Soc. Trop. Med. Hyg. 2009, 103, 1113-1120. [CrossRef] [PubMed]

27. Kawada, H.; Higa, Y.; Futami, K.; Muranami, Y.; Kawashima, E.; Osei, J.H.N.; Sakyi, K.Y.; Dadzie, S.; de Souza, D.K.; Appawu, M.; et al. Discovery of Point Mutations in the Voltage-Gated Sodium Channel from African Aedes aegypti Populations: Potential Phylogenetic Reasons for Gene Introgression. PLoS Negl. Trop. Dis. 2016, 10, e0004780. [CrossRef] [PubMed]

28. Moyes, C.L.; Vontas, J.; Martins, A.J.; Ng, L.C.; Koou, S.Y.; Dusfour, I.; Raghavendra, K.; Pinto, J.; Corbel, V.; David, J.P.; et al. Contemporary status of insecticide resistance in the major Aedes vectors of arboviruses infecting humans. PLoS Negl. Trop. Dis. 2017, 11, 1-20. [CrossRef] [PubMed] 
29. Saavedra-Rodriguez, K.; Urdaneta-Marquez, L.; Rajatileka, S.; Moulton, M.; Flores, A.E.; Salas, F.-; Bisset, J.; Rodriguez, M.; Mccall, P.J.; Donnelly, M.J.; et al. A mutation in the voltage-gated sodium channel gene associated with pyrethroid resistance in Latin American Aedes aegypti. Insect Mol Biol 2007, 16, 785-798. [CrossRef] [PubMed]

30. Brengues, C.; Hawkes, N.J.; Chandre, F.; Mccarroll, L.; Duchon, S.; Guillet, P.; Manguin, S.; Morgan, J.C.; Hemingway, J. Pyrethroid and DDT cross-resistance in Aedes aegypti is correlated with novel mutations in the voltage-gated sodium channel gene. Med. Vet. Entomol. 2003, 17, 87-94. [CrossRef] [PubMed]

31. Hu, Z.; Du, Y.; Nomura, Y.; Dong, K. A sodium channel mutation identified in Aedes aegypti selectively reduces cockroach sodium channel sensitivity to type I, but not type II pyrethroids. Insect Biochem. Mol. Biol. 2011, 4, 9-13. [CrossRef]

32. Du, Y.; Nomura, Y.; Satar, G.; Hu, Z.; Nauen, R.; He, S.Y.; Zhorov, B.S.; Dong, K. Molecular evidence for dual pyrethroid-receptor sites on a mosquito sodium channel. Proc. Natl. Acad. Sci. USA 2013, 110, 11785-11790. [CrossRef]

33. Badolo, A.; Sombié, A.; Pignatelli, P.M.; Sanon, A.; Yaméogo, F.; Wangrawa, D.W.; Sanon, A.; Kanuka, H.; McCall, P.J.; Weetman, D. Insecticide resistance levels and mechanisms in Aedes aegypti populations in and around Ouagadougou, Burkina Faso. PLoS Negl. Trop. Dis. 2019, 13, e0007439. [CrossRef]

34. Vontas, J.G.; Small, G.J.; Hemingway, J. Glutathione S-transferases as antioxidant defence agents confer pyrethroid resistance in Nilaparvata lugens. Biochem. J. 2001, 357, 65-72. [CrossRef]

35. Hemingway, J.; Hawkes, N.J.; McCarroll, L.; Ranson, H. The molecular basis of insecticide resistance in mosquitoes. Insect Biochem. Mol. Biol. 2004, 34, 653-665. [CrossRef] [PubMed]

(C) 2020 by the authors. Licensee MDPI, Basel, Switzerland. This article is an open access article distributed under the terms and conditions of the Creative Commons Attribution (CC BY) license (http://creativecommons.org/licenses/by/4.0/). 